\title{
Summary of the Stockholm Micro 1980 Tournament - December 1980
}

\author{
Sven-Gunnar Samuels on*
}

Compared to last year's competition, the play has been considerably improved, as can be seen from the end results. In the 1979 tournament, the Challenger family dominated the picture completely. But this year, the best Challenger machine had to be satisfied with appearing in the lower half of the result table (see below).

Mephisto $\mathrm{X}$ was particularly impressive in the two final rounds. The final game against MYCHESS was a jewel. If you so wish, you might call it a breakthrough for microcomputer chess.

The Sargon programs performed approximately as expected. That is, they played a stable and careful style of chess without any extravagances. Boris 2.5 and Sargon ARB could perhaps have done even better if the end-game play were more polished.

The Challenger computer was not successful this year. The programs have not improved very much over last year and, therefore, the competitors have gained on them with respect to chess knowledge.

The Swedish programs Rook 4.0 and Princhess were disappointing this time and did not perform as well as they had in the London tournament in September.

Both Lars Karlsson and Ulf Rathsman had made "improvements" in their programs for the Stockholm tournament and these turned out to have exactly the opposite effect.

Quite remarkable was the fact that just before the tournament, Princhess beat Mephisto X in a couple of "warm-up" games; but then, in the tournament, it did not get a single point.

But then, chess is a peculiar game...

Results

Final

Position

Program

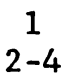

5

$6-7$

8

Mephis to X
MYCHESS
Sargon ARB
Boris 2.5 MGS
Challenger VSC
Rook 4.0/4.5
Challenger S8
Princhess

\section{Points}

$2 \frac{1}{2}$

2

2

$1 \frac{1}{2}$

1

0 (continued on page 13)

*Reprinted from ICCA-Sweden PLY $1 / 1981$ and kindly translated by Dr. Christina Enroth-Cugell of the Department of Electrical Engineering at Northwestern University - and Johan Enroth's sister. ed. 
Mephis to X (leve1 6) - MYCHESS (leve1 4)

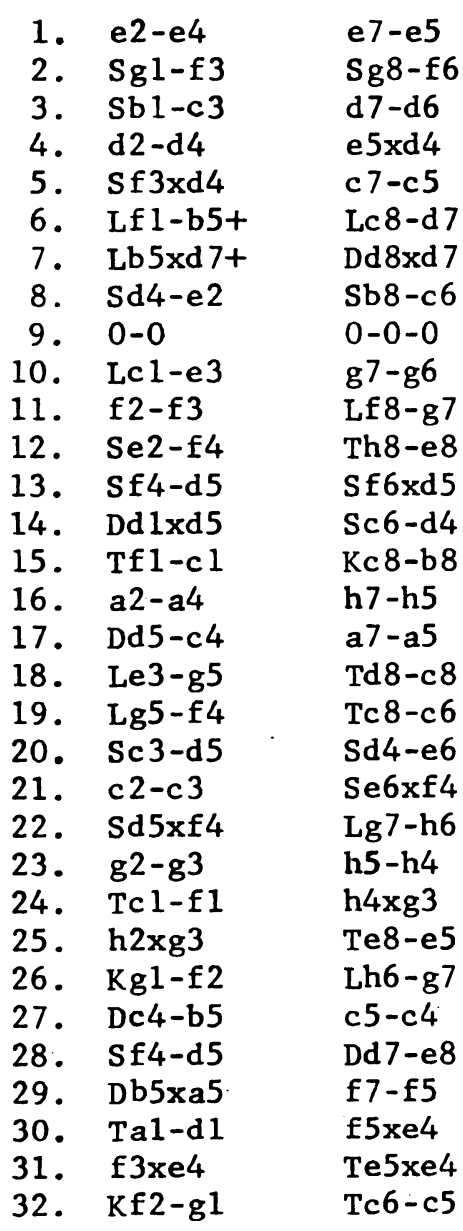

Note re German algebraic notation: $S=k n i g h t, L=b i s h o p, T=r o o k$, $\mathrm{D}=$ queen, $\mathrm{K}=\mathrm{king}$

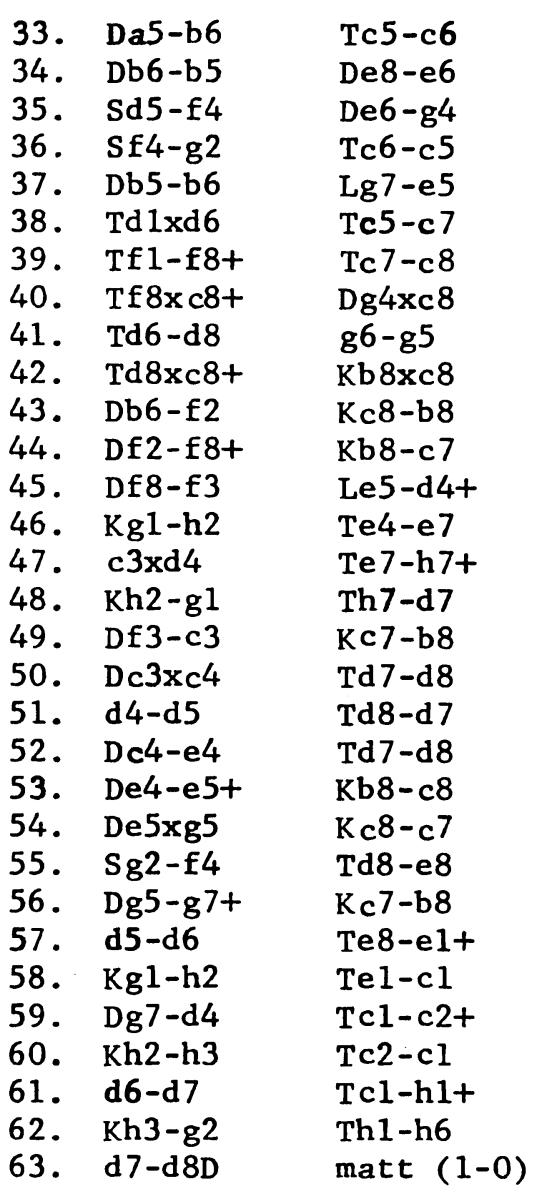

